\title{
Transpedicular-Transdiscal Cement Augmentation Treatment of Thoracolumbar Fusion Proximal Junctional Failure
}

\author{
MARY K. JESSE, MD, ANDREW W. CLEVELAND III, MD, MICHAEL J. REITER, MD, VIKAS V. PATEL, \\ MD, CHRISTOPHER J. KLECK, MD \\ University of Colorado, Aurora, Colorado
}

\begin{abstract}
Background: Long instrumented fusions for adult deformity have a proximal junction kyphosis rate between $20 \%$ and $40 \%$. When symptomatic, proximal junctional failure (PJF) often requires revision surgery and is associated with significant morbidity. Vertebral cement augmentation (VCA) has been used for prophylaxis against PJF but has not been previously described as treatment after onset of PJF has occurred. We describe a series of patients with PJF of long posterior spinal fusions that were treated at our institution using a novel VCA technique.

Methods: Three patients with PJF above thoracolumbopelvic fusions were retrospectively reviewed following treatment with transpedicular-transdiscal VCA. The medical record was reviewed for demographic data, outcomes scores, and radiographic images.

Results: Mean age was 69.3 years. Mean follow-up was 13.3 months. Mean preprocedure visual analog scale score was 8.67, and postprocedure visual analog scale score was 4.00. Mean preprocedure sagittal balance was $9.7 \mathrm{~cm}$, and postprocedure sagittal balance was $5.8 \mathrm{~cm}$. No patients required revision surgery for PJF in the follow-up period.

Conclusions: Transpedicular-transdiscal VCA treatment for PJF is safe and may have the potential to prevent the need for revision surgery.
\end{abstract}

Level of Evidence: 4.

Complications

Keywords: proximal junctional failure, proximal junctional kyphosis, vertebral cement augmentation, kyphoplasty, vertebroplasty

\section{INTRODUCTION}

Long instrumented fusions for adult spinal deformity are fraught with complications, including the development of kyphosis at the transition segment between the fused and mobile spine. Radiographic proximal junction kyphosis (PJK) has been defined as a proximal junctional sagittal Cobb angle $\geq 10^{\circ}$ and at least $10^{\circ}$ greater than preoperative measurements. ${ }^{1,2}$ The incidence of reported proximal junction kyphosis (PJK) ranges between $20 \%$ and $40 \%{ }^{2,3}$; however, this represents a spectrum of manifestations from inconsequential radiographic findings to symptomatic disease, sometimes requiring revision surgery. Most instances of PJK occur within 3 months of surgery. ${ }^{2,4,5}$ There are surgical, radiographic, and patient-specific risk factors that may lead to the development of PJK. ${ }^{2,3,6-10}$ Fracture at the upper instrumented vertebrae is the most common mechanism for the development of PJK. ${ }^{2,7}$ Proximal junction failure (PJF) generally refers to radiographic findings of PJK coupled with adverse clinical symptoms that can include increasing pain, functional impairment, and even neurologic deficits in severe cases. ${ }^{3,11}$ Some definitions for PJF include the need for revision surgery. ${ }^{2}$ Revision surgery can be corrective of PJF deformity but is associated with significant additional morbidity that might otherwise be avoided if the onset of PJF can be prevented, delayed, or treated. $^{12}$ Vertebral cement augmentation (VCA) has been described as a prophylactic measure to prevent $\mathrm{PJF}^{2,3,13,14}$; however, these instances looked at preventing PJF above an instrumented construct before it occurred. This case report seeks to describe 3 patients where a unique technique of VCA was used to address PJF of long thoracolumbar fusions in order to avoid revision surgery. 
Table 1. Summary of patient data.

\begin{tabular}{|c|c|c|c|c|c|c|c|c|c|}
\hline & $\begin{array}{l}\text { Age, } \\
\mathbf{y}\end{array}$ & $\begin{array}{c}\text { Existing } \\
\text { Construct }\end{array}$ & $\begin{array}{c}\text { PJF Pathology } \\
\text { Level(s) }\end{array}$ & $\begin{array}{c}\text { SVA, } \\
\text { cm }\end{array}$ & $\begin{array}{l}\text { Procedure } \\
\text { Levels }\end{array}$ & $\begin{array}{c}\text { Preprocedure } \\
\text { VAS }\end{array}$ & $\begin{array}{c}\text { Postprocedure } \\
\text { VAS }\end{array}$ & $\begin{array}{l}\text { Follow-up } \\
\text { SVA }\end{array}$ & $\begin{array}{c}\text { Follow-up, } \\
\mathbf{y}\end{array}$ \\
\hline Patient 1 & 75 & T11-Pelvis & $\mathrm{T} 10-\mathrm{T} 11$ & 8.3 & T10-T11 & 9 & 6 & 6.1 & $>3$ \\
\hline Patient 2 & 65 & T6-Pelvis & T5 & 14 & T4-T6 & 7 & 0 & 6.5 & $>3$ \\
\hline Patient 3 & 68 & T10-Pelvis & T9-T10 & 6.8 & T8-T10 & 10 & 6 & 4.8 & $>3$ \\
\hline Average & 69.333 & & & 9.7 & & 8.666 & 4 & 5.8 & \\
\hline STD & 4.190 & & & 3.102 & & 1.247 & 2.828 & 0.726 & \\
\hline
\end{tabular}

Abbreviations: PJF, proximal junctional failure; STD, standard deviation; SVA, sagittal vertical axis; VAS, visual analog scale.

\section{MATERIALS AND METHODS}

This study was exempt from approval by our Institutional Review Board. The electronic medical record was retrospectively reviewed for radiographic and clinical data for all patients identified to have undergone this technique.

Descriptive statistics were used for demographics and outcomes data (Table).

\section{RESULTS}

Three patients had multiple prior thoracolumbar surgeries and preexisting instrumentation and fusion from the thoracic spine to the pelvis. See the Table for a summary of patient information. Each patient presented to the clinic with new-onset focal proximal junctional back pain and radiographic findings of PJF, including increased junctional kyphosis, positive sagittal imbalance, and fractures of the upper instrumented and proximal noninstrumented vertebrae.

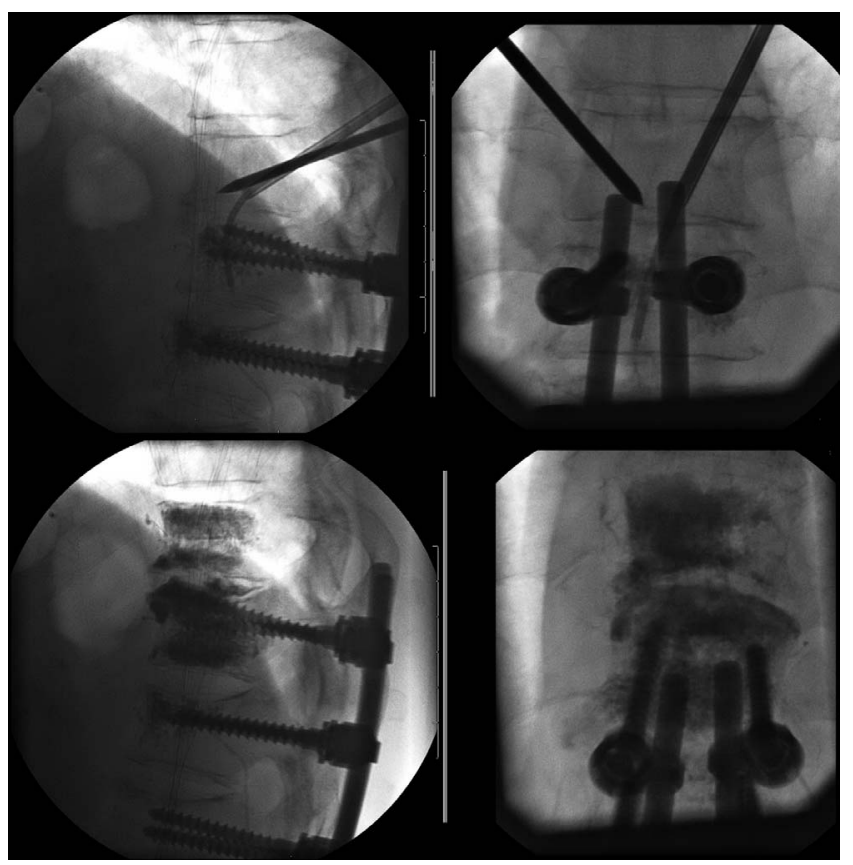

Figure 1. Fluoroscopic procedure images of patient 1.
Each patient underwent vertebroplasty by an interventional radiologist. A cannula was placed in percutaneous fashion into the proximal noninstrumented level. A curette or drill was used to create a cavity across the disc space that allowed a curved needle to introduce the cannula from the proximal noninstrumented level into the disc space and the upper instrumented vertebra. Cement was introduced into each upper instrumented vertebra, the intervening disc space, and the affected proximal noninstrumented vertebral bodies. There was no cement extravasation. No complications were associated with the procedures. Refer to Figures 1, 2, and 3 for fluoroscopy procedure images.

All patients had postprocedure relief of pain. Sagittal balance was improved based on available radiographic information from 2 of 3 patients. See Figures 4, 5, and 6 for comparison of preprocedure and follow-up standing lateral radiographs of patients 1, 2, and 3, respectively. None of the

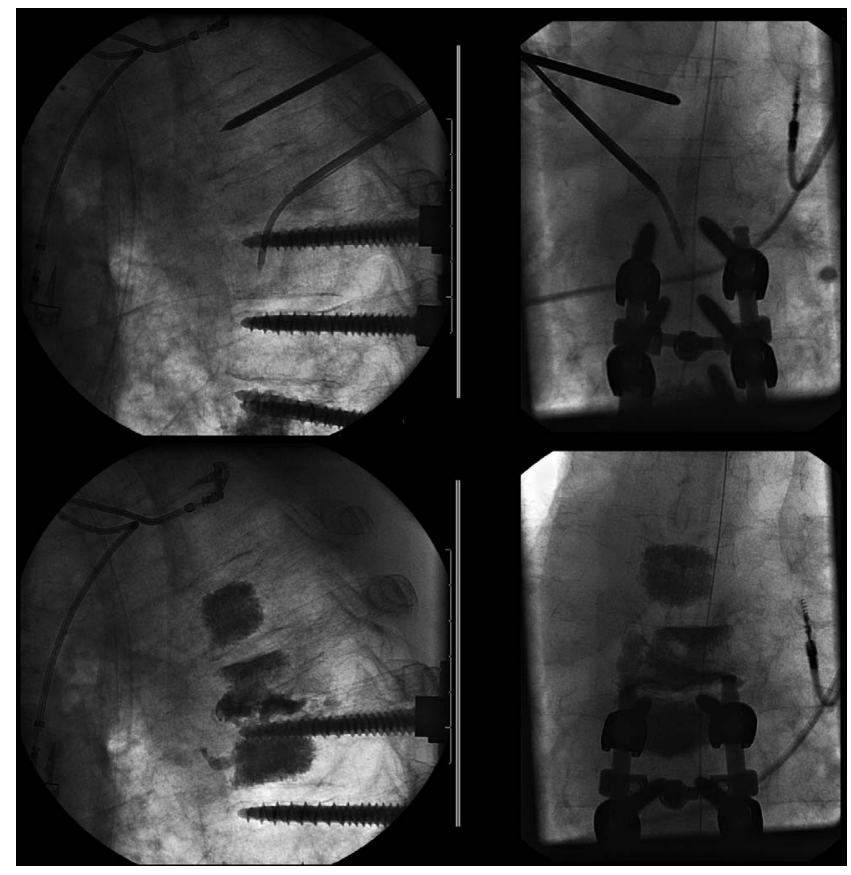

Figure 2. Fluoroscopic procedure images of patient 2. 


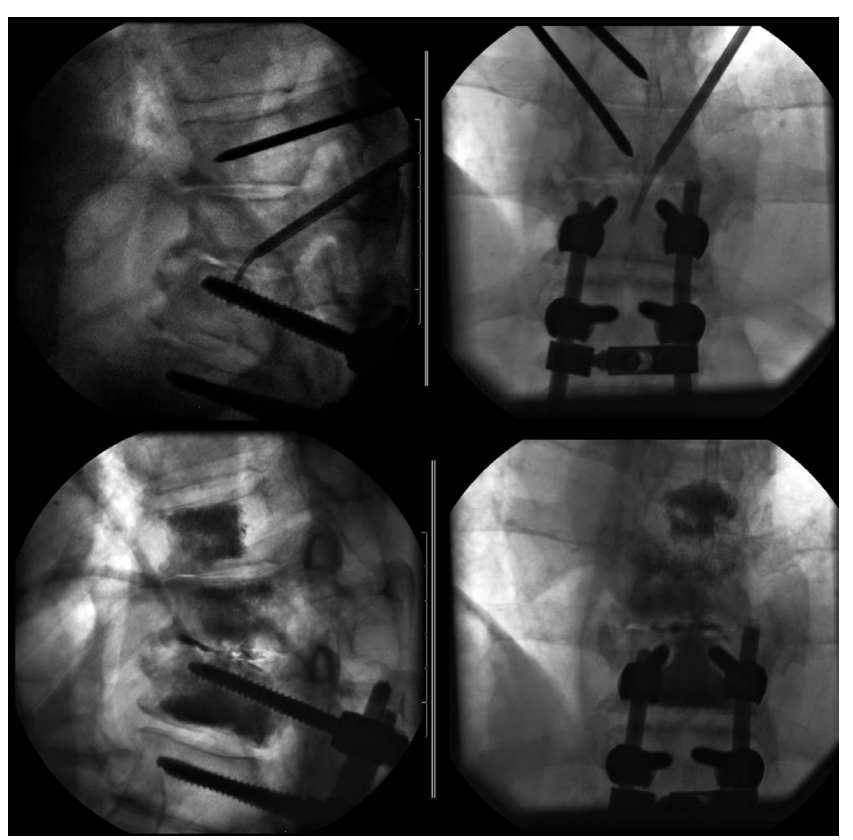

Figure 3. Fluoroscopic procedure images of patient 3.

patients have gone on to revision surgery at $>3$ year follow-up.

\section{DISCUSSION}

The role of VCA in the management of PJF has primarily been described as a prophylactic measure. ${ }^{2,3}$ Prophylactic vertebroplasty has been found to be cost-effective compared with revision instrumented fusion, ${ }^{13}$ and to be effective in reducing junctional fractures in biomechanical cadaver models. ${ }^{14}$ Preliminary clinical results after prophylactic

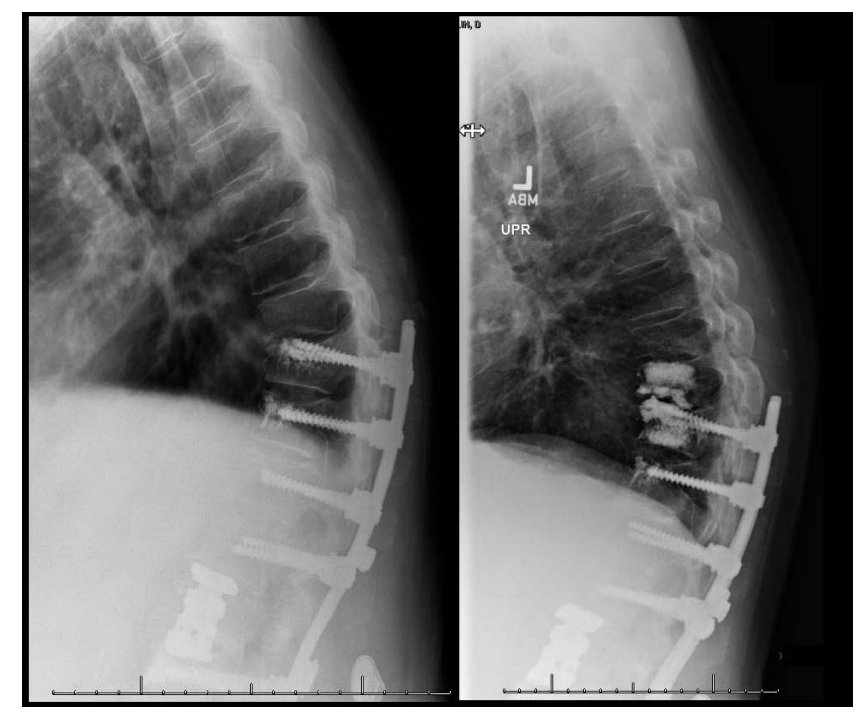

Figure 4. Preprocedure and postprocedure standing lateral radiographs of patient 1.

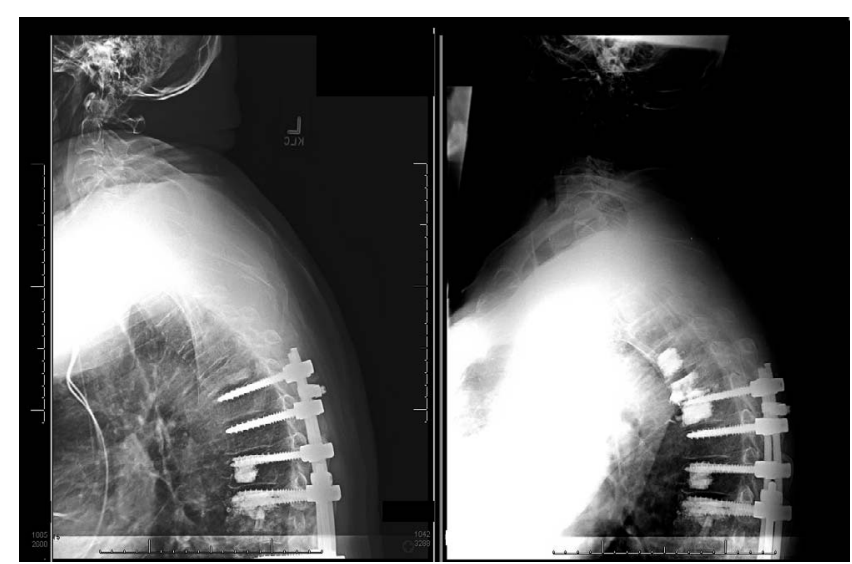

Figure 5. Preprocedure and postprocedure standing lateral radiographs of patient 2.

vertebroplasty are promising for reducing the incidence of PJF and PJK. ${ }^{15}$ There is no published literature that describes VCA as a treatment for PJF after it has occurred.

In this case study, we present 3 instances of PJF above long instrumented posterior fusions where a unique technique for VCA was used for treatment. Percutaneous trans-end plate vertebroplasty of the upper instrumented vertebrae and the disc space, in addition to the affected supra-adjacent levels, resulted in stabilization of the junctional failure, relief of pain, and avoidance of revision surgery at $>3$-year follow-up. The disc space was injected to stabilize across the disc and to stabilize the screws, which had penetrated the superior end plate of the upper instrumented level. Further, this technique was felt to prevent collapse through the soft disc and allow continuous anterior column stability.

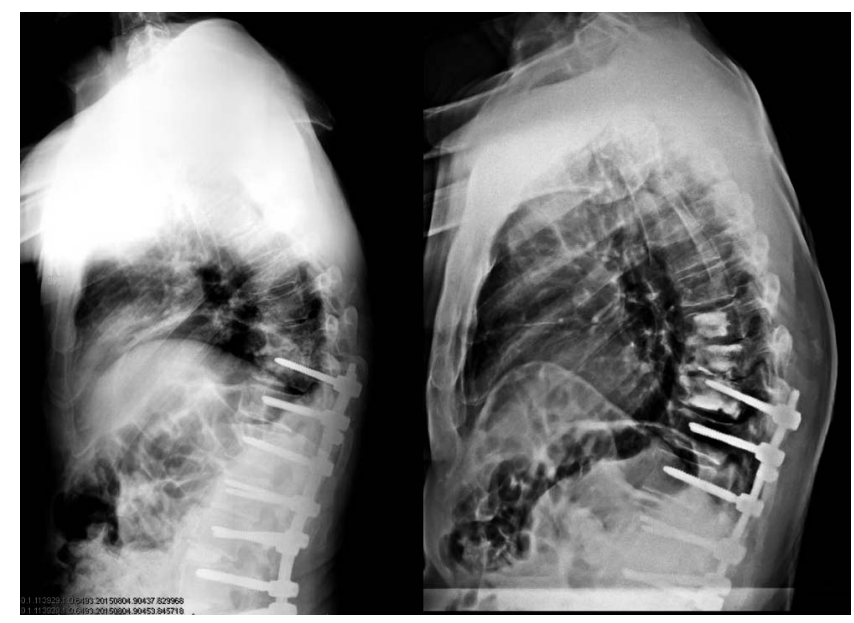

Figure 6. Preprocedure and postprocedure standing lateral radiographs of patient 3. 
Vertebral cement augmentation has some evidence supporting its use for prophylactic prevention of PJF. This study suggests that a modified VCA technique may be used as treatment for PJF after onset has occurred. There exists the potential to halt progression of junctional failure and obviate the need for revision surgery. Further study of more patients during a longer follow-up period will be required to examine the natural course of VCAtreated PJF and its progression to or avoidance of revision surgery. Collection of outcome scores and radiographic assessments as well as evaluation of comparison groups during a longer period may provide more significant evidence for the efficacy of this method to address PJF.

\section{REFERENCES}

1. Glattes RC, Bridwell KH, Lenke LG, Kim YJ, Rinella A, Edwards C. Proximal junctional kyphosis in adult spinal deformity following long instrumented posterior spinal fusion: incidence, outcomes, and risk factor analysis. Spine (Phila Pa 1976). 2005;30(14):1643-1649.

2. Kim HJ. Proximal junctional kyphosis. J Am Acad Orthop Surg. 2016;24(5):318-326.

3. Lau D, Clark AJ, Scheer JK, et al. Proximal junctional kyphosis and failure following spinal deformity surgery: a systematic review of the literature as a background to classification development. Spine (Phila Pa 1976). 2014;39(25):2093-2102.

4. Yagi M, King AB, Boachie-Adjei O. Incidence, risk factors, and natural course of proximal junctional kyphosis: surgical outcomes review of adult idiopathic scoliosis: minimum 5 years of follow-up. Spine (Phila Pa 1976). 2012;37(17):14791489.

5. Park SJ, Lee CS, Chung SS, Lee JY, Kang SS, Park SH. Different risk factors of proximal junctional kyphosis and proximal junctional failure following long instrumented fusion to the sacrum for adult spinal deformity: survivorship analysis of 160 patients. Neurosurgery. 2017;80(2):279-286.

6. Kim YJ, Bridwell KH, Lenke LG, Glattes CR, Rhim S, Cheh G. Proximal junctional kyphosis in adult spinal deformity after segmental posterior spinal instrumentation and fusion. Spine (Phila Pa 1976). 2008;33(20):2179-2184.

7. Maruo K, Ha Y, Inoue $\mathrm{S}$, et al. Predictive factors for proximal junctional kyphosis in long fusions to the sacrum in adult spinal deformity. Spine (Phila Pa 1976). 2013;38(23):E1469-E1476.

8. McClendon J, Smith TR, Sugrue PA, Thompson SE, O'Shaughnessy BA, Koski TR. Spinal implant density and postoperative lumbar lordosis as predictors for the development of proximal junctional kyphosis in adult spinal deformity. World Neurosurg. 2016;95:419-424.

9. Wang $H$, Yang D, Wang $T$, et al. Incidence and risk factors for the progression of proximal junctional kyphosis in degenerative lumbar scoliosis following long instrumented posterior spinal fusion. Medicine (Baltimore). 2016;95(32):e4443.

10. Yan P, Bao H, Qiu Y, et al. Mismatch between proximal rod contouring and proximal junctional angle. Spine (Phila Pa 1976). 2017;42(5):E280-E287.

11. Kim HJ, Bridwell KH, Lenke LG, et al. Proximal junctional kyphosis results in inferior SRS pain subscores in adult deformity patients. Spine (Phila Pa 1976). 2013;38(11):896-901.

12. Kim YC, Lenke LG, Bridwell KH, et al. Results of revision surgery for proximal junctional kyphosis following posterior segmental instrumentation. Spine (Phila Pa 1976). 2016;41(24):E1444-E1452.

13. Hart RA, Prendergast MA, Roberts WG, Nesbit GM, Barnwell SL. Proximal junctional acute collapse cranial to multi-level lumbar fusion: a cost analysis of prophylactic vertebral augmentation. Spine J. 2008;8(6):875-881.

14. Kebaish KM, Martin CT, O'Brien JR, Lamotta IE, Voros GD, Belkoff SM. Use of vertebroplasty to prevent proximal junctional fractures in adult deformity surgery: a biomechanical cadaveric study. Spine J. 2013;13(12):1897-1903.

15. Martin CT, Skolasky RL, Mohamed AS, Kebaish KM. Preliminary results of the effect of prophylactic vertebroplasty on the incidence of proximal junctional complications after posterior spinal fusion to the low thoracic spine. Spine Deform. 2013;1(2):132-138.

Disclosures and COl: The authors received no funding for this study and report no conflicts of interest.

Corresponding Author: Andrew W. Cleveland III, MD, c/o Claire Cofer, 12605 E 16th Ave, Stop F712, Aurora, CO 80045. Phone: (303) 7241588; Email: Andrew.cleveland@ucdenver.edu, Andrew.cleveland86@gmail.com, Claire.cofer@ ucdenver.edu.

Published 31 October 2019

This manuscript is generously published free of charge by ISASS, the International Society for the Advancement of Spine Surgery. Copyright (C) 2019 ISASS. To see more or order reprints or permissions, see http://ijssurgery.com. 